\title{
Evaluation of different GCM models and climate change scenarios using LARS_WG model in simulating meteorological data (Case study: Shiraz synoptic station, Fars Province, Iran)
}

\author{
Seyed Amir Shamsnia ${ }^{1}$, Nader Pirmoradian ${ }^{2}$ \\ ${ }^{I}$ (Department of Water Engineering, Shiraz Branch, Islamic Azad University, Shiraz, Iran) \\ ${ }^{2}$ (Department of Water Engineering, Faculty of Agricultural Sciences, University of Guilan, Rasht, Iran)
}

\begin{abstract}
In recent years, the topic of climate change in effect of greenhouse gases increase has been lionized in scientific studies. Hence the prediction and evaluation of meteorological parameters changes in effect of climate change is very important. LARS is a model that generates weather data and predicts weather parameters by downscaling general circulation models (GCM). In this study, in order to evaluate 15 GCM models performance in simulating the meteorological data of Shiraz station synoptic (2011-2012), statistical downscaling of each model under scenarios of approved climate change by the IPCC was performed by LARS model. The parameters of precipitation, radiation, minimum and maximum temperature were tested. The Results showed that for precipitation, downscaling INCM3 model had the best performance in terms of minimum error, under A1B scenario for radiation, , both GFCM21 and CSMK3 models had the best performance in terms of minimum error under $\mathrm{A} 1 \mathrm{~B}$ and $\mathrm{B} 1$ scenarios, respectively. The simulation results of minimum temperature with downscaling FGOALS model under B1 scenario indicated more accuracy than other models. For maximum temperature, both GIAOM and CSMK3 models had the best performance in terms of minimum error under A1B and B1 scenarios, respectively.
\end{abstract}

Keywords: - General circulation model, LARS, Statistical downscaling, Shiraz.

\section{INTRODUCTION}

Climate is a complicated system and is changing based on available evidences due to changing value of greenhouse gases and human activities. Through predicting and studying the rate of meteorology parameters changes proper approaches can be chosen for decreasing fatal effects of climate change phenomenon. One of the most valid methods for evaluating the effects of climate change phenomenon is using simulating climatic variables by general circulation models (GCM). These models can predict changes resulted from the effect of greenhouse gas on meteorology parameters. Where these models have low spatial resolution power, the output of these models should be downscale. To do this, one of two dynamic or statistical methods is used [2]. One of the instruments for downscaling of these models statistically is using LARS model. LARS model is predicted meteorology parameters for a time period in the future by using a series of meteorology data and downscaling output of one of the GCM models. Indeed LARS model, as a producer of meteorology data, is simulated meteorology parameters through output downscaling of GCM models.

In a study, LARS model's ability in simulating meteorology data of Golestan Province has been examined in 1993-2007. The results of this model represented that the most error is in simulating data than real ones related to the sunshine hours variable and precipitation, maximum and minimum temperature variables have been simulated properly [5]. Similarly, in another research, season changes of climate parameters in the next 20 years is examined by using HADCM3 model data exponential downscaling by means of LARS software based on three scenarios approved by Intergovernment Panel on Climate Change (IPCC) including A1B, A2, B1 (pessimistic, moderate, optimistic respectively) in Khorasan Razavi province. The results showed that climate condition of the province in the next 20 years has a significant difference with the current condition [1]. Semenov et al., (2002) compared the efficiency of both LARS and WGEN models in 18 synoptic stations of America, Europe and Asia and concluded that LARS model produces better consequences [6]. Bazrafshan et al., (2009), after examining the ability of both LARS and ClimGen models for simulating meteorology variables of Iran concluded that LARS model has a better performance for simulating two precipitation and radiation parameters, but temperature parameter is simulated better by ClimGen model [3]. In researches a general circulation model for simulating climatic variables has been mostly used and the comparison between the efficiency of kinds of general circulation model has been considered fewer. In this research, 15 general circulation models with available climate change scenario for each model, is downscaling by LARS model and the ability and accuracy of this model in simulating precipitation, radiation, maximum and minimum variables of each models and scenario existed for the same model is evaluated. 


\section{MATERIALS AND METHODS}

The case study is located in Shiraz, Fars province, west-south of Iran and the required meteorology data was obtained from synoptic station of Shiraz. LARS model is a meteorology data producer used Markov chain and semi-empirical distribution method for precipitation simulation and probability of its occurrence, semiempirical distribution method for radiation simulation and Fourier series for temperature modeling [7]. For this model two input files is needed; the first file includes the name of a station, geography longitude and latitude, and elevation; the second file includes precipitation, minimum and maximum temperature and radiation variables or sunshine hours in a studied station. The model is analyzed these data obtained from a text file including statistical specifications of meteorology parameters during base period. Then, LARS model is simulated meteorology parameters during the requested period considering GCM model as well as a scenario selected by the operator. In this study, for LARS-WG5 model, 1981-2010 period is considered as monitoring period and Shiraz synoptic station meteorology data in this period is given to the model. Then the model is approved by IPCC for downscaling of $15 \mathrm{GCM}$ models with climate change scenarios. General circulation models including CGMR, CSMK3, FGOALS, GFCM21, GIAOM, HADCM3, HADGEM, INCM3, IPCM4, MIHR, MPEH5, NCCCSM, NCPCM, BCM2 and CNCM3 are examined. These models are different in terms of spatial resolution power, design institute, predictability of atmospheric variables, and predictability of oceanic variables [4]. In table. 1, available climate change scenario for each general circulation model in LARS-WG 5.5 software and in table. 2, specifications of climate change scenarios have been used.

After running the software for all 15 GCM models, with available scenarios, the monthly output data average of a model is compared with the observed data for 2011-2012 period to determine which small-scale of GCM model with which scenario has better ability in simulating meteorology data. Precipitation, radiation, maximum and minimum temperature parameters are studied. To compare this, Pearson's correlation coefficient $\left(\mathrm{R}^{2}\right)$, the Relative Root Mean-Square Error (RRMSE) and Mean Absolute Error (MAE) were used as following equations.

$$
\begin{gathered}
\text { RRMSE }=\left(\sqrt{\frac{\sum_{i=1}^{n}\left(X_{i}-Y_{i}\right)^{2}}{n}}\right)\left(\frac{100}{\bar{X}}\right) \\
M A E=\frac{\sum_{i=1}^{n}\left|X_{i}-Y_{i}\right|}{n}
\end{gathered}
$$

In these equations $\mathrm{X}_{\mathrm{i}}$ and $\mathrm{Y}_{\mathrm{i}}$, are measured and simulated values respectively, $\mathrm{i}$ is a representative of months of a year and $\mathrm{X}$ is the average of observed data.

Table. 1. Climate change Scenarios for each model

\begin{tabular}{cc}
\hline The scenarios are approved by IPCC & Model \\
\hline A1B & CGMR \\
A1B, B1 & CSMK3 \\
A1B, B1 & FGOALS \\
A1B, A2, B1 & GFCM21 \\
A1B, B1 & GIAOM \\
A1B, A2, B1 & HADCM3 \\
A1B, A2 & HADGEM \\
A1B, A2, B1 & INCM3 \\
A1B, A2, B1 & IPCM4 \\
A1B, B1 & MIHR \\
A1B, A2, B1 & MPEH5 \\
A1B, A2, B1 & NCCCSM \\
A1B, A2 & NCPCM \\
A1B, B1 & BCM2 \\
A1B, A2 & CNCM3 \\
\hline
\end{tabular}


Table. 2. Specifications of climate change scenarios [1]

\begin{tabular}{cc}
$\begin{array}{c}\text { Climate change } \\
\text { scenario }\end{array}$ & Specifications \\
\hline A1B & $\begin{array}{c}\text { Rapid economic growth, maximum population growth during half century } \\
\text { and after that decreasing trend, rapid modern and effective technology growth } \\
\text { Rapid world population growth, heterogeneous economics in direction of } \\
\text { regional conditions throughout the world }\end{array}$ \\
B1 & $\begin{array}{r}\text { Population convergence throughout the world, change in economic structure } \\
\text { (pollutant reduction and introduction to clean technology resources) }\end{array}$ \\
\hline
\end{tabular}

\section{RESULTS}

The scatter plot of monthly observed values of precipitation, radiation, maximum and minimum temperature against downscaling values of CGMR model with A1B scenario has been shown in figures 1, 2, 3, 4 as a sample respectively. As it seen, simulation accuracy for temperature and radiation parameters is generally more than precipitation.

To evaluate simulation accuracy of different models, $\mathrm{R}^{2}$, RRMSE and MAE values obtained from the process of evaluating models in 2011-2012 for Shiraz synoptic station have been shown in tables 3, 4, 5, 6 respectively. Considering Pearson coefficient $\left(\mathrm{R}^{2}\right)$ which is observable in these tables, this coefficient in precipitation parameter is lower than other parameters and is changed in a limitation of 0.49-0.72 (table. 3). Other parameters presented very high coefficient. Considering table 3, RRMSE statistical precipitation parameter concerning precipitation values close to zero and lower in region and an equation related to statistics, very high values observed for statistic (values between 73.38-109.39). Thus, considering region condition using this statistic was not proper for evaluation, so MAE statistic was only analyzed. The MAE values were between 0.45-0.70. The least value was related to GFCM21 model with A1B scenario (0.45). Therefore, GFCM21 model with pessimist scenario was presented as the most accurate model for estimating precipitation parameter in studied region. In table. 4, statistics studied the radiation parameter have been shown. Concerning this table, MAE value for radiation was between 0.93-1.94 and the least value (0.93) was for GFCM21 model with A1B scenario. Similarly, RRMSE was around 5.23-6.04 and the least value (5.23) was for CSMK3 with B1 scenario. Hence, GFCM21 and CSMK3 models with A1B and B1 scenarios respectively were recognized as the best models for the estimation of radiation parameter in studied region. Values related to minimum temperature parameter have been provided in table. 5. MAE values varied between 1.23-1.89. The least MAE value is related to FGOALS model with B1 scenario with the value of 1.23. RPMSE value was also around 14.20-20.30 and the least value was related to FGOALS model with B1 scenario with the value of $14.20 \%$. Thus, FGOALS model with optimist scenario (B1) with the least MAE and RPMSE values presented the most accurate simulation. Maximum temperature parameter with the value provided in table 6 presented MAE values around 0.64-1.19. The least MAE value (0.64) is related to GIAOM model with A1B scenario. Also according to this table RRMSE values were between 3.41-5.58. The least value of this statistic is related to CSMK3 model with B1 scenario (3.41). Therefore, GIAOM model with pessimist scenario and CSMK3 model with optimist scenario were shown the most accurate simulation for minimum temperature parameter in Shiraz region.

\section{CONCLUSION}

Considering evaluations performed generally, one can say that LARS model is proper for meteorology prediction variable in Shiraz region. To predict minimum temperature parameter using downscaling results of FGOALS model with B1 scenario the most accurate results are obtained. Maximum temperature parameter of GIAOM and CSMK3 models with $\mathrm{A} 1 \mathrm{~B}$ and B1 scenarios respectively, have the best results and are recommended. GFCM21 and CSMK3 models with A1B and B1 scenarios were presented as the most accurate models for radiation parameter. GFCM21 model with A1B scenario is recommended for the prediction of precipitation. By using the results of this research in long-term planning related to meteorology prediction and climate change phenomenon in Shiraz region, accurate results are obtained. 


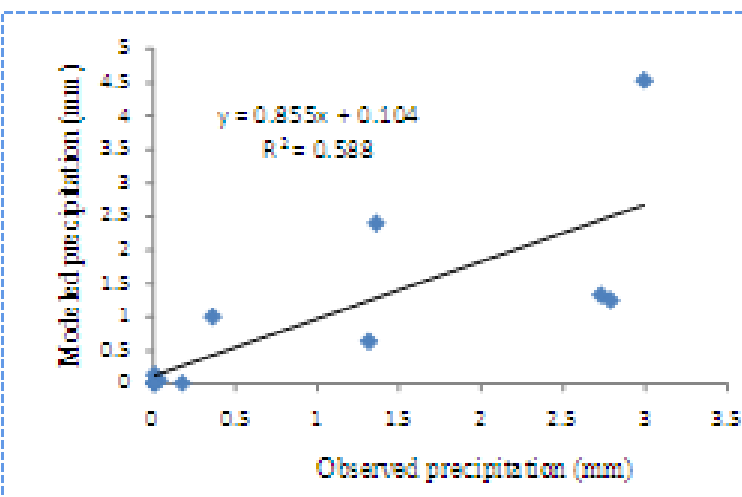

Figure. 1. Observed and modeled monthly precipitation scatter plot related to CGMR with AlB scenario (2011-2012)

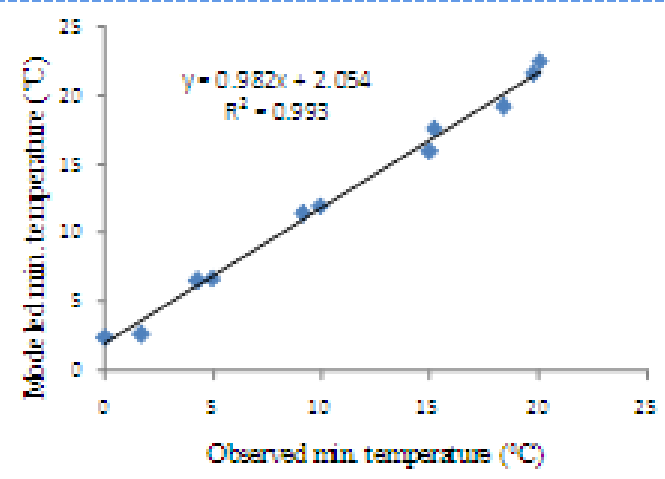

Figure. 3. Observed and modeled monthly minimum temperature scatter plot related to CGMR with AlB scenario (2011-2012)

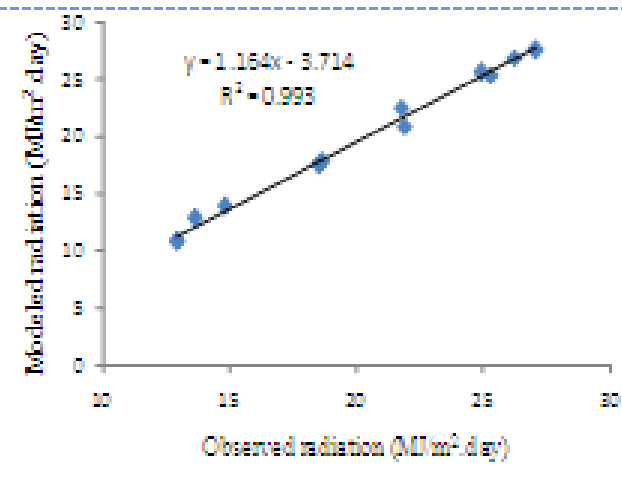

Figure. 2. Observed and modeled monthly radiation scatter plot related to CGMIR with AlB scenario (2011-2012)

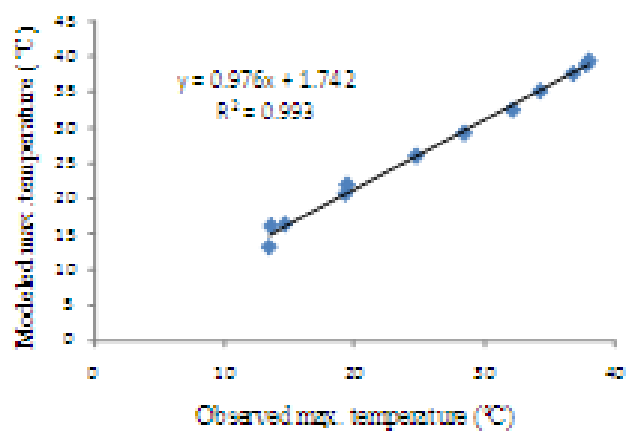

Figure. 4. Observed and modeled monthly maximum temperature scatter plot related to CGMIR with AlB scenario (2011-2012)

Table. 3. MAE, RRMSE and $\mathbf{R}^{2}$ values for evaluating different GCM models in 2011-2012 for precipitation.

\begin{tabular}{|c|c|c|c|c|}
\hline $\mathrm{R} 2$ & RRMSE & MAE & Scenario & Model \\
\hline 0.588 & 87.29 & 0.60 & A1B & CGMR \\
\hline 0.597 & 81.65 & 0.56 & A1B & \multirow{2}{*}{ CSMK3 } \\
\hline 0.591 & 80.91 & 0.54 & $\mathrm{~B} 1$ & \\
\hline 0.578 & 81.49 & 0.54 & A1B & \multirow{2}{*}{ FGOALS } \\
\hline 0.617 & 76.73 & 0.48 & B1 & \\
\hline 0.624 & 78.83 & 0.45 & A1B & \multirow{3}{*}{ GFCM21 } \\
\hline 0.620 & 76.84 & 0.48 & $\mathrm{~A} 2$ & \\
\hline 0.581 & 81.29 & 0.53 & B1 & \\
\hline 0.596 & 81.19 & 0.55 & A1B & \multirow{2}{*}{ GIAOM } \\
\hline 0.589 & 80.15 & 0.52 & $\mathrm{~B} 1$ & \\
\hline 0.623 & 76.79 & 0.51 & A1B & \multirow{3}{*}{ HADCM3 } \\
\hline 0.610 & 78.92 & 0.53 & $\mathrm{~A} 2$ & \\
\hline 0.612 & 77.27 & 0.50 & B1 & \\
\hline 0.603 & 82.24 & 0.51 & A1B & \multirow{2}{*}{ HADGEM } \\
\hline 0.567 & 101.82 & 0.66 & $\mathrm{~A} 2$ & \\
\hline 0.555 & 106.11 & 0.69 & A1B & \multirow{3}{*}{ INCM3 } \\
\hline 0.571 & 109.39 & 0.69 & $\mathrm{~A} 2$ & \\
\hline 0.581 & 90.98 & 0.61 & B1 & \\
\hline 0.545 & 86.31 & 0.58 & A1B & \multirow[b]{2}{*}{ IPCM4 } \\
\hline 0.488 & 106.63 & 0.70 & $\mathrm{~A} 2$ & \\
\hline
\end{tabular}


Evaluation of different GCM models and climate change scenarios using LARS_WG model in

\begin{tabular}{|c|c|c|c|c|}
\hline 0.556 & 87.94 & 0.60 & $\mathrm{~B} 1$ & \\
\hline 0.558 & 81.42 & 0.54 & A1B & \multirow{2}{*}{ MIHR } \\
\hline 0.608 & 79.51 & 0.53 & B1 & \\
\hline 0.582 & 81.31 & 0.50 & A1B & \multirow{3}{*}{ MPEH5 } \\
\hline 0.641 & 75.73 & 0.49 & $\mathrm{~A} 2$ & \\
\hline 0.513 & 91.15 & 0.60 & $\mathrm{~B} 1$ & \\
\hline 0.595 & 80.06 & 0.54 & A1B & \multirow{3}{*}{ NCCCSM } \\
\hline 0.608 & 81.37 & 0.56 & $\mathrm{~A} 2$ & \\
\hline 0.601 & 79.77 & 0.54 & B1 & \\
\hline 0.622 & 88.80 & 0.55 & A1B & \multirow{2}{*}{ NCPCM } \\
\hline 0.649 & 73.38 & 0.46 & $\mathrm{~A} 2$ & \\
\hline 0.590 & 80.15 & 0.52 & A1B & \multirow{2}{*}{ BCM2 } \\
\hline 0.721 & 80.36 & 0.50 & $\mathrm{~B} 1$ & \\
\hline 0.599 & 80.00 & 0.47 & A1B & \multirow{2}{*}{ CNCM3 } \\
\hline 0.570 & 84.13 & 0.57 & $\mathrm{~A} 2$ & \\
\hline
\end{tabular}

Table. 4. MAE, RRMSE and $\mathbf{R}^{2}$ values for evaluating different GCM models in 2011-2012 for radiation.

\begin{tabular}{|c|c|c|c|c|}
\hline $\mathrm{R} 2$ & RRMSE & MAE & Scenario & Model \\
\hline 0.993 & 5.43 & 0.95 & A1B & CGMR \\
\hline 0.992 & 5.26 & 0.96 & A1B & \multirow{2}{*}{ CSMK3 } \\
\hline 0.992 & 5.23 & 0.97 & B1 & \\
\hline 0.992 & 5.59 & 0.98 & A1B & \multirow{2}{*}{ FGOALS } \\
\hline 0.991 & 5.49 & 0.96 & B1 & \\
\hline 0.991 & 5.43 & 0.93 & A1B & \multirow{3}{*}{ GFCM21 } \\
\hline 0.99 & 5.57 & 0.95 & $\mathrm{~A} 2$ & \\
\hline 0.991 & 5.62 & 0.99 & B1 & \\
\hline 0.99 & 5.79 & 0.97 & A1B & \multirow{2}{*}{ GIAOM } \\
\hline 0.99 & 5.63 & 0.97 & B1 & \\
\hline 0.991 & 5.58 & 0.98 & A1B & \multirow{3}{*}{ HADCM3 } \\
\hline 0.992 & 5.70 & 1.01 & $\mathrm{~A} 2$ & \\
\hline 0.992 & 5.42 & 0.93 & B1 & \\
\hline 0.991 & 5.67 & 0.97 & A1B & \multirow{2}{*}{ HADGEM } \\
\hline 0.991 & 6.02 & 1.02 & $\mathrm{~A} 2$ & \\
\hline 0.991 & 5.44 & 0.98 & A1B & \multirow{3}{*}{ INCM3 } \\
\hline 0.992 & 5.48 & 0.99 & $\mathrm{~A} 2$ & \\
\hline 0.992 & 5.47 & 1.00 & B1 & \\
\hline 0.991 & 5.47 & 0.94 & A1B & \multirow{3}{*}{ IPCM4 } \\
\hline 0.99 & 5.91 & 1.03 & $\mathrm{~A} 2$ & \\
\hline 0.991 & 5.72 & 0.99 & B1 & \\
\hline 0.99 & 5.74 & 0.97 & A1B & \multirow{2}{*}{ MIHR } \\
\hline 0.99 & 5.85 & 1.01 & B1 & \\
\hline 0.991 & 5.54 & 0.98 & A1B & \multirow{3}{*}{ MPEH5 } \\
\hline 0.991 & 5.46 & 0.98 & $\mathrm{~A} 2$ & \\
\hline 0.99 & 5.44 & 0.95 & B1 & \\
\hline 0.991 & 5.69 & 0.98 & A1B & \multirow{3}{*}{ NCCCSM } \\
\hline 0.991 & 5.63 & 0.96 & $\mathrm{~A} 2$ & \\
\hline 0.992 & 5.41 & 0.94 & B1 & \\
\hline
\end{tabular}


Evaluation of different GCM models and climate change scenarios using LARS_WG model in

\begin{tabular}{ccccc}
\hline 0.991 & 5.65 & 1.00 & A1B & NCPCM \\
0.991 & 5.39 & 0.96 & A2 & A1B \\
\hline 0.991 & 5.30 & 0.95 & B1 & BCM2 \\
0.991 & 5.26 & 0.93 & A1B & CNCM3 \\
\hline 0.991 & 5.77 & 1.00 & A2 & \\
\hline 0.991 & 6.04 & 1.04 & & \\
\hline
\end{tabular}

Table. 5. MAE, RRMSE and $\mathbf{R}^{2}$ values for evaluating different GCM models in 2011-2012 for minimum

\begin{tabular}{|c|c|c|c|c|}
\hline $\mathrm{R}^{2}$ & RRMSE & MAE & Scenario & Model \\
\hline 0.993 & 20.12 & 1.89 & A1B & CGMR \\
\hline 0.991 & 14.56 & 1.26 & A1B & \multirow{2}{*}{ CSMK3 } \\
\hline 0.992 & 14.31 & 1.26 & B1 & \\
\hline 0.991 & 14.35 & 1.24 & A1B & \multirow{2}{*}{ FGOALS } \\
\hline 0.992 & 14.20 & 1.23 & $\mathrm{~B} 1$ & \\
\hline 0.992 & 18.57 & 1.71 & A1B & \multirow{3}{*}{ GFCM21 } \\
\hline 0.992 & 17.99 & 1.65 & $\mathrm{~A} 2$ & \\
\hline 0.992 & 17.42 & 1.59 & $\mathrm{~B} 1$ & \\
\hline 0.992 & 14.86 & 1.31 & A1B & \multirow{2}{*}{ GIAOM } \\
\hline 0.993 & 15.01 & 1.35 & B1 & \\
\hline 0.993 & 15.32 & 1.39 & A1B & \multirow{3}{*}{ HADCM3 } \\
\hline 0.993 & 16.85 & 1.55 & $\mathrm{~A} 2$ & \\
\hline 0.993 & 14.72 & 1.32 & B1 & \\
\hline 0.992 & 18.83 & 1.74 & A1B & \multirow{2}{*}{ HADGEM } \\
\hline 0.992 & 18.36 & 1.69 & $\mathrm{~A} 2$ & \\
\hline 0.992 & 18.22 & 1.68 & A1B & \multirow{3}{*}{ INCM3 } \\
\hline 0.989 & 19.36 & 1.76 & A2 & \\
\hline 0.990 & 16.71 & 1.48 & B1 & \\
\hline 0.991 & 17.28 & 1.56 & A1B & \multirow{3}{*}{ IPCM4 } \\
\hline 0.993 & 16.18 & 1.47 & A2 & \\
\hline 0.992 & 16.21 & 1.46 & B1 & \\
\hline 0.992 & 19.88 & 1.84 & A1B & \multirow{2}{*}{ MIHR } \\
\hline 0.991 & 20.30 & 1.88 & B1 & \\
\hline 0.993 & 17.25 & 1.58 & A1B & \multirow{3}{*}{ MPEH5 } \\
\hline 0.993 & 17.04 & 1.57 & A2 & \\
\hline 0.993 & 15.49 & 1.41 & B1 & \\
\hline 0.992 & 18.78 & 1.73 & A1B & \multirow{3}{*}{ NCCCSM } \\
\hline 0.992 & 18.44 & 1.70 & A2 & \\
\hline 0.993 & 18.52 & 1.72 & $\mathrm{~B} 1$ & \\
\hline 0.993 & 15.35 & 1.37 & A1B & \multirow{2}{*}{ NCPCM } \\
\hline 0.993 & 14.52 & 1.29 & A2 & \\
\hline 0.993 & 14.76 & 1.34 & A1B & \multirow{2}{*}{ BCM2 } \\
\hline 0.993 & 14.49 & 1.29 & B1 & \\
\hline 0.993 & 17.13 & 1.58 & A1B & \multirow{2}{*}{ CNCM3 } \\
\hline 0.993 & 16.98 & 1.55 & A2 & \\
\hline
\end{tabular}


Evaluation of different GCM models and climate change scenarios using LARS_WG model in

Table. 6. MAE, RRMSE and $\mathbf{R}^{2}$ values for evaluating different GCM models in 2011-2012 for maximum temperature.

\begin{tabular}{|c|c|c|c|c|}
\hline $\mathrm{R}^{2}$ & RRMSE & MAE & Scenario & Model \\
\hline 0.993 & 5.26 & 1.19 & A1B & CGMR \\
\hline 0.993 & 3.48 & 0.73 & A1B & \multirow{2}{*}{ CSMK3 } \\
\hline 0.994 & 3.413 & 0.70 & B1 & \\
\hline 0.993 & 3.63 & 0.70 & A1B & \multirow{2}{*}{ FGOALS } \\
\hline 0.993 & 3.60 & 0.69 & B1 & \\
\hline 0.994 & 4.76 & 0.97 & A1B & \multirow{3}{*}{ GFCM21 } \\
\hline 0.993 & 4.52 & 1.00 & A2 & \\
\hline 0.993 & 4.36 & 0.94 & $\mathrm{~B} 1$ & \\
\hline 0.993 & 3.424 & 0.64 & A1B & \multirow{2}{*}{ GIAOM } \\
\hline 0.994 & 3.59 & 0.71 & $\mathrm{~B} 1$ & \\
\hline 0.994 & 3.69 & 0.78 & A1B & \multirow{3}{*}{ HADCM3 } \\
\hline 0.993 & 4.25 & 0.89 & $\mathrm{~A} 2$ & \\
\hline 0.994 & 3.57 & 0.75 & B1 & \\
\hline 0.993 & 4.82 & 1.01 & A1B & \multirow{2}{*}{ HADGEM } \\
\hline 0.994 & 4.67 & 0.96 & $\mathrm{~A} 2$ & \\
\hline 0.994 & 4.57 & 0.98 & A1B & \multirow{3}{*}{ INCM3 } \\
\hline 0.993 & 4.66 & 0.97 & A2 & \\
\hline 0.994 & 4.20 & 0.91 & $\mathrm{~B} 1$ & \\
\hline 0.993 & 4.30 & 0.90 & A1B & \multirow{3}{*}{ IPCM4 } \\
\hline 0.994 & 3.96 & 0.81 & $\mathrm{~A} 2$ & \\
\hline 0.994 & 3.85 & 0.82 & B1 & \\
\hline 0.992 & 5.58 & 1.19 & A1B & \multirow{2}{*}{ MIHR } \\
\hline 0.993 & 5.49 & 1.16 & B1 & \\
\hline 0.994 & 4.31 & 0.90 & A1B & \multirow{3}{*}{ MPEH5 } \\
\hline 0.994 & 4.27 & 0.89 & $\mathrm{~A} 2$ & \\
\hline 0.994 & 3.83 & 0.77 & B1 & \\
\hline 0.993 & 4.81 & 1.03 & A1B & \multirow{3}{*}{ NCCCSM } \\
\hline 0.993 & 4.72 & 1.02 & $\mathrm{~A} 2$ & \\
\hline 0.994 & 4.66 & 1.01 & $\mathrm{~B} 1$ & \\
\hline 0.993 & 3.84 & 0.76 & A1B & \multirow{2}{*}{ NCPCM } \\
\hline 0.993 & 3.58 & 0.73 & $\mathrm{~A} 2$ & \\
\hline 0.995 & 3.55 & 0.66 & A1B & \multirow{2}{*}{ BCM2 } \\
\hline 0.995 & 3.71 & 0.73 & B1 & \\
\hline 0.993 & 4.35 & 0.90 & A1B & \multirow{2}{*}{ CNCM3 } \\
\hline 0.993 & 4.30 & 0.89 & A2 & \\
\hline
\end{tabular}

\section{REFERENCES}

[1] Ashraf , B., Mousavi Baygi, M. Kamali, G.A. and Davari, K. Prediction of Seasonal Variations of Climatological Parameters over Next 20 Years by Using Statistical Downscaling Method of HADCM3 Data (Case Study: Khorasan Razavi Province). Journal of Water and Soil. 25(4), 2011, 945-957.

[2] Babaeian, I., Najafi-nik, Z., Zabol Abbassi, F., Habibi Nokhandan, M., Adab, H. and Malbousi, H. Climate Change Assessment over Iran During 2010-2039 by Using Statistical Downscaling of ECHO- G Model. Geography and Development Journal, 16, 2009, 135-152.

[3] Bazrafshan, J., Khalili, A., Hoorfar, A., Torabi, S. and Hajjam, S. Comparison of the Performance of ClimGen and LARS-WG Models in Simulating the Weather Factors for Diverse Climates of Iran. IranWater Resources Research, 5(1), 2009, 12-14.

[4] IPCC 4th Assessment Report. See also URL http://www.IPCC.ch. 2007

[5] Meshkati, A.H., Kord-jazi. And Babaeian, I. 2010. Evaluation of LARS Model in Simulating Meteorology Data of Golestan Province in 1993-2007. Geographical Science Applied Research Journal, 16(19), 2007, 81-96.

[6] Semenov, M.A., Brooks, R.J., Barrow, E.M., and Richardson, C.W., 1998. Comparison of the WGEN and LARS Stochastic Weather Generators in Diver's Climates. Climate Research, 10, 1998, 95-107.

[7] Semenov, M.A. and Barrow, E.M.. A Stochastic Weather Generator for Use in Climate. User' Impact Studies Manual, Version 3.0. 2002. 